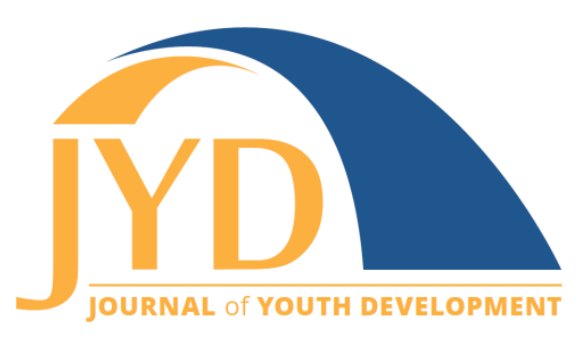

http://jyd. pitt. edu/ | Vol. 14 Issue 1 DOI 10.5195/jyd.2019.637 | ISSN 2325-4017 (online)

\title{
Family Problem-Solving and Attachment Quality: Associations With Adolescent Risk-Taking Behavior
}

\author{
Angela Keyzers \\ University of Minnesota \\ holt0647@umn.edu \\ Lindsey Weiler \\ University of Minnesota \\ Imweiler@umn.edu \\ Shelley Haddock \\ Colorado State University \\ shaddock@colostate.edu \\ Jennifer Doty \\ University of Florida \\ jennifer.doty@ufl.edu
}

\begin{abstract}
Close parent-child relationships are protective against the development of delinquent behavior. By creating a context for open communication and trust, parents positively influence adolescent development. The current study examined the associations among attachment quality, family problemsolving, and adolescent risk-taking behavior, as well as the mediating effect of family problem-solving on the relationship between attachment quality and adolescent risk-taking behavior. Participants included 520 adolescents (ages 10 to $19, \mathrm{M}=14.24$ ) and their parents or guardians $(\mathrm{N}=520$ ). Two path analyses were conducted to test study hypotheses. As predicted, attachment quality was negatively associated with parent and adolescent perceptions of adolescent risk-taking behavior and positively related to family problem-solving ability, after controlling for age, gender, and race/ethnicity. Contrary to our hypothesis, family problem-solving ability did not mediate the effect of attachment quality on parent or youth perceptions of adolescent risk-taking behavior. Preventive interventions that encourage warm, supportive bonds between parents and youth may aid families in deterring youth from negative risk-taking behavior. Further research should examine other family-level factors that might influence adolescent risk-taking via direct and indirect pathways.
\end{abstract}

(cc) EY New articles in this journal are licensed under a Creative Commons Attribution 4.0 License. This journal is published by the University Library System, University of Pittsburgh and is cosponsored by the University of Pittsburgh Press. The Journal of Youth Development is the official peer-reviewed publication of the National Association of Extension 4-H Agents and the National AfterSchool Association. 
Key words: adolescence, family problem-solving, attachment quality, risk-taking

Adolescence is a time of rapid transitions characterized by various physical, social, emotional, cognitive and behavioral changes (Sarracino \& Innamorati, 2012). For many adolescents, the occurrence of these changes coincides with exploration with a wide range of risk-taking behaviors. For instance, between the ages of 12 and 25, many adolescents initiate involvement in several health-risk behaviors including substance use and delinquency (DiClemente, Santelli, \& Crosby, 2009). The term risk-taking is defined as engagement in behaviors in which the outcome remains uncertain, with the possibility of a negative health outcome (Irwin, 1993). Consistent with prior research, risk-taking refers to three health-risk behaviors including substance use, violence, and delinquency (Garrido, Weiler, \& Taussig, 2017).

While adolescence is characterized by greater autonomy, parents continue to play an important role in the lives of their adolescent children (Haggerty, Skinner, Catalano, Abbott, \& Crutchfield, 2015; Pilgrim, Schulenberg, O’Malley, Bachman, \& Johnston, 2006). Parents are a major socializing agent of children throughout childhood (Chassin, Curran, Hussong, \& Colder, 1996; Pequegnat \& Szapocznik, 2000) and can promote protective qualities against the development and maintenance of problem behaviors (Hawkins, Catalano, \& Miller, 1992). Research suggests that a warm, close relationship between parents and adolescents is negatively associated with adolescent risk-taking behavior (Mogro-Wilson, 2008; Yun, Cui, \& Blair, 2016). When parents were perceived by their children as being warm and affectionate, adolescents were more likely to communicate with their parents (Yun et al., 2016). However, further research is needed to elucidate the mechanism by which close parent-child relationships affect adolescent risk-taking behavior, so that interventions may be more precise in influencing such behavior.

\section{Family Problem-Solving and Adolescent Risk-Taking}

One aspect of parent-child relationships that may relate to adolescent risk-taking is family problem-solving. Family problem-solving is the family's ability to resolve problems in order to maintain effective functioning (Miller, Ryan, Keitner, Bishop, \& Epstein, 2000). While little research has been done in this area, evidence of its potential influence can be drawn from research on individual problem-solving. Individual problem-solving is defined as "the selfdirected cognitive-behavioral process by which a person attempts to identify or discover effective or adaptive solutions to problems encountered in everyday living" (D'Zurilla, Nezu, \& Maydeu-Olivares, 2007, p.12). Individual problem-solving abilities in adolescents are negatively associated with risk-taking behaviors including aggression, delinquency, and substance abuse 
Family Problem Solving, Attachment, Risk-Taking

(Botvin, Malgady, Griffin, Scheier, \& Epstein, 1998; Jaffee \& D'Zurilla, 2003; Mushtaq, 2007). Based on social problem-solving theory, it has been hypothesized that adolescents with greater problem-solving abilities will be able to respond adaptively and appropriately to situations in which externalizing behavior is one way to respond (D'Zurilla \& Nezu, 1999; Jaffee \& D'Zurilla, 2003). In addition, it has been posited that parents who are good problem solvers are more equipped to manage their child's externalizing behaviors and to help their children successfully solve problems (Jaffee \& D'Zurilla, 2003; Vuchinich, 2004). While previous research has linked individual problem solving to risk-taking (Jaffee \& D'Zurilla, 2003), family problem-solving has been less explored. Researchers have suggested conjoint problem-solving training to prevent behavioral problems during adolescence (Montemayor, 1986; Robin \& Foster, 1989), but the basic research needed to justify this approach has not been examined.

Family problem-solving is unique from individual problem-solving in that it facilitates effective interaction between multiple members of a family in order to solve challenges (Ahmadi, AzadMarzabadi, Ashrafi, \& Raiisi, 2007). For example, when an adolescent is struggling with substance use, it can be helpful for the family to work together to come up with different ways to solve the problem. As follows, difficult issues can be tackled as a family and adolescents are not left to solve problems on their own. Family problem-solving is also important in that it accounts for the interconnectedness of individual family members and forces us to recognize that the behaviors of one family member can impact the behavior of all other family members. In families where family problem-solving is part of the norm, adolescents may come to learn how beneficial the process is for them and may seek support in this way.

Although there is evidence to suggest a relationship between family problem-solving and adolescent risk-taking, it is limited and dated. For instance, Borduin, Henggeler, Hanson, and Pruitt (1985) found that lower rates of parent-adolescent problem-solving were negatively associated with adolescent delinquent behavior. Results of another study showed that families of substance-using adolescents exhibited low levels of parent-adolescent problem-solving (Hops, Tildesley, Lichtenstein, Ary, \& Sherman, 1991). Also relatively unexplored is the relationship between parent-child relationship quality and family problem-solving ability, but one study did find that parental warmth was positively associated with the level of family problem-solving in a sample of at-risk (i.e., families with a child at risk for conduct disorder), referred (i.e., families with a preadolescent child referred for treatment of behavior problems), and comparison families (Vuchinich, Wood, \& Vuchinich, 1994). Due to the dearth of recent empirical literature, theoretical concepts are needed. The application of attachment theory and 
Family Problem Solving, Attachment, Risk-Taking

family systems theory (FST) provides some guidance for hypothesizing these relationships and implications that extend from the results.

\section{Theoretical Foundations}

\section{Attachment to Parents and Risk-Taking Behavior}

According to attachment theory, a strong emotional and physical bond to a primary caregiver is critical to development (Bowlby, 1969/1982; Cassidy \& Shaver, 2008). Secure attachment is established through constant, loving, and supportive behavior by a parent or other caretaker. During adolescence, attachment to parents is believed to have a role in internalizing and externalizing behavior. A study by Cooper, Shaver, and Collins (1998) examined individual differences in attachment styles (i.e., secure, anxious, avoidant-ambivalent) as predictors of adjustment in a sample of adolescents and found that adolescents with insecure attachment styles reported higher levels of drug involvement than their securely-attached counterparts.

Attachment security may also be related to the quality of communication between adolescents and their parents (Cassidy, 2001). When attempting to solve conflicts with their parents, securely attached youth tend to engage in useful discussions, display relational competence, and flexible working models of the relationship. As a result, youth with secure attachment to parents develop the skills necessary to regulate their emotions and manage their impulses (Grossmann, Grossmann, Kindler, \& Zimmermann, 2008). On the other hand, insecure parentchild dyads are more likely to display problem-solving difficulties, withdraw from disagreements, and/or become hostile and oppressive (Allen, 2008).

The protective effect of parental attachment security is thought to be related to the development of appropriate self-regulation abilities in adolescents. Adolescents who have a secure attachment to their parents are more likely to display self-regulation abilities such as self-control and adaptive coping strategies (Kobak, Cole, Ferenz-Gillies, Fleming, \& Gamble, 1993; Li, Delvecchio, Lis, Nie, \& Di Riso, 2015). They may also be more likely to communicate with their parent about social problems they face (e.g., pressure from peers to engage in substance use), as well as discuss problem-solving strategies for addressing such pressures. It is therefore plausible that adolescents with greater attachment quality to a caregiver will have greater family problem-solving skills, which will in turn be associated with less engagement in health-risk behaviors including substance use, violence, and delinquency. While family problemsolving may be associated with factors such as family communication and conflict management, 
the unique contribution of family problem-solving is its focus on skills directly related to resolving problems, such as identifying the problem and possible solutions, choosing a path and following through, and revising the relative success of that solution. These skills not only help with the immediate problem, they help to maintain effective family functioning (Epstein, Baldwin, \& Bishop, 1983).

\section{Family Systems Theory}

Family systems theory (FST; Boss, Doherty, LaRossa, Schumm, \& Steinmetz, 1993) was derived from general systems theory and is used to explain the behavior of complex organized family systems. According to the theory, the family is a system of interconnected and interdependent individuals and none of these individuals can be understood in isolation from the larger family system (Boss et al., 1993). A unique contribution of FST in risk-taking research is that it allows researchers to view individuals as nested in other systems and to view relationships as reciprocal. FST posits that risk-taking outcomes of adolescents are shaped by the interacting behaviors of the parent and child; therefore, it requires researchers to examine the interactions of all family members as opposed to individual-level processes. In the same way, family processes, such as problem-solving, can be understood as an extension of the quality of the parent-child relationship. For example, an adolescent struggling with violent behavior may benefit from discussing ways to confront situations that trigger violent behavior. Absent a positive relationship, families may avoid engaging in problem-solving or may do so ineffectively. On the other hand, a family who regularly discusses problems and alternative strategies may be able to support the adolescent in handling triggering situations to minimize future violent behavior. By conceptualizing the mechanism by which relationship quality affects certain outcomes as relational, the emphasis shifts away from individual members to the complex reciprocal relationships among members, which is more representative of an adolescent's reality.

FST posits that the behaviors of individuals in a family system mutually influence each other (Boss et al., 1993). That is, one person's behavior generally affects every other individual within the system. For instance, the risk-taking behavior of an adolescent impacts the relationships between the adolescent and parents, as the family is now faced with the task of solving the adolescent's substance use behavior in order to maintain healthy family functioning. The current study examines how the behaviors of parents and adolescent children affect adolescent risktaking behavior. One FST concept of particular importance to the research question is feedback loops. Feedback loops are defined as "a closed path, along which information can be traced 
Family Problem Solving, Attachment, Risk-Taking

from one point in a system, through one or more other parts of the system or its environment, and back to the point of origin" (Boss et al., 1993, p. 334). Although this study does not address feedback loops specifically, it stands to reason that identifying mechanisms within the family system that promote positive risk-taking outcomes for adolescents will advance knowledge on the influence of parents on risk-taking behavior during adolescent development. If attachment quality and family problem-solving can be traced to adolescent risk-taking behavior, adolescent risk-taking may influence the quality of the relationship and future problem-solving. Positive feedback loops, therefore, could be identified to help facilitate change in a system that is maintaining a dysfunctional homeostasis. Using a family systems approach is uniquely appropriate for developing family-focused prevention programs.

\section{Purpose}

The purpose of this study was to examine associations among family problem-solving, attachment quality, and adolescent risk-taking behavior, and to examine whether perceptions of problem-solving within the family mediate the relationship between attachment quality and adolescent risk-taking behavior. Based on previous research linking attachment quality with individual problem-solving and individual problem-solving with adolescent risk-taking, greater attachment with a caregiver may create an environment that fosters greater family problemsolving abilities, in turn affecting adolescent engagement in risk-taking behavior. Examining these relationships will provide researchers with a deeper understanding of how specific aspects of the parent-child relationship relate to adolescent risk-taking behavior.

Specific hypotheses are: (a) family problem-solving ability will be negatively associated with both parent- and youth-reported adolescent risk-taking behavior, (b) youth perceptions of attachment quality with their caregiver will be negatively associated with both parent and youth reported adolescent's risk-taking behavior, (c) family problem-solving ability will be positively associated with youth perceived attachment quality, and (d) family problem-solving ability will mediate the effect of youth perceived attachment quality on youth and parent reports of adolescent risk-taking behavior. 


\section{Method}

Secondary data analysis was conducted after obtaining institutional review board (IRB) approval from the University of Minnesota. The original study was approved by the IRB at Colorado State University.

\section{Participants}

There were 522 youth and 520 parents/guardians who originally provided consent, but two youth withdrew consent resulting in a sample of 520 youth. Youth ranged in age from 10 to 19 years $(M=14.24, S D=1.79)$. Nine youth did not provide data on their age. Of the sample, 229 youth participants were female (44\%), 290 were male $(55.8 \%)$ and one identified as transgender $(0.2 \%)$. The majority of the youth in the sample $(57.1 \%)$ described themselves as White, $26.5 \%$ described themselves as Hispanic, $9.6 \%$ as Mixed, $3.5 \%$ as Black or African American, $1.7 \%$ as American Indian or Alaska Native, and $0.4 \%$ as Asian (non-exclusive categories). Six youth did not report on their race/ethnicity.

The parent participant group was comprised of 428 (82.3\%) females, 79 (15.2\%) males, and $13(2.5 \%)$ who did not disclose. The average age of parents was 45 years $(S D=9.31)$, ranging from 26 to 77 years. Of the parent participant group, $12(2.3 \%)$ did not disclose their race/ethnicity. Of those who did, $67.5 \%$ described themselves as White (Caucasian/nonHispanic), $21.3 \%$ as Hispanic, $5.6 \%$ as Mixed, $1.3 \%$ as Black, $1.2 \%$ as Asian and $0.8 \%$ as American Indian or Alaska Native (non-exclusive categories).

\section{Procedure}

Participants for the study were obtained as part of a larger study of Campus Connections (a 12week, after-school mentoring program for at-risk youth; Weiler, Haddock, Henry, Zimmerman, Krafchick, \& Youngblade, 2015). For the purposes of the larger study, youth were referred by community agencies in Northern Colorado to Campus Connections. To be eligible to participate, adolescents had to be between 11 and 18 years old (youth who were 10 years-old at the intake were eligible to participate as long as they turned 11 during the program) and experiencing at least one risk factor as indicated on the individual and environmental risk assessment (Herrera, DuBois, \& Grossman, 2013). Informed assent and consent were obtained from youth and at least one parent/guardian. Data for the current study included baseline data collected via Qualtrics from all participants sampled at the start of the Fall 2015/16 and Spring 2016/17 semesters, prior to any involvement in the intervention. Youth and parent(s)/guardian(s) were 
each compensated $\$ 10$ for completing the baseline survey. A subset of measures was identified for the study.

\section{Demographics}

\section{Youth}

Age was calculated using three items: month mentee was born, year mentee was born, and date of the baseline survey. Gender was obtained using a single item: "What is your gender?" Respondents chose one option: "Male", "Female," or "Transgender." Youth were also asked: "What is your race and ethnicity?" Participants chose all options that applied to them from a list of racial and ethnic groups: "American Indian or Alaska Native," "Asian," "Black/African American," "Hispanic/Latino," "Native Hawaiian or Other Pacific Islander," "White," or "Mixed." Prior to analysis, race/ethnicity was recoded to form a dichotomous minority/non-minority variable.

\section{Parents}

Gender was obtained using a single item: "What is your gender?" Respondents chose one option: "Male," "Female," or "Transgender." Parent age was calculated by subtracting one item: "What year were you born?" from the year the data were collected (e.g., 2016 minus 1946). Parents provided information about their race or ethnicity using the item: "What is your race and ethnicity?" Participants chose all options that applied to them from a list of racial and ethnic groups: "American Indian or Alaska Native," "Asian," "Black/African American," "Hispanic/Latino," "Native Hawaiian or Other Pacific Islander," "White," or "Mixed."

\section{Attachment Quality}

Attachment quality with youth's caregiver was measured using the 15-item Inventory of Parent and Peer Attachment-Short Form (IPPA-Short Form; Gifford-Smith, 2000). Youth were asked to rate the extent to which they believed each item was true about the person or people who care for them on a 3-point scale ( $1=$ Not true, $2=$ Sometimes true, $3=$ Always true), with higher scores indicating greater perceived attachment. Of the original 15 IPPA items, one was dropped from the scale due to its sensitive nature (i.e., scared at home with parents). The final IPPA scale included items such as "my parent(s) care about me". Cronbach's alpha for attachment in this sample was .89. 


\section{Family Problem-Solving}

Youth and parent perceptions of family problem-solving was measured using the problemsolving subscale of the McMaster Family Assessment Device (Epstein et al. 1983). Based on systems theory, the McMaster Model of Family Functioning assumes that a family's level of functioning cannot be understood on an individual basis and that the reciprocal behaviors of family members strongly influence the behavior of individual family members (Miller et al., 2000). The problem-solving subscale is comprised of five items such as: "we try to think of different ways to solve problems," "we confront problems involving feelings," and "we usually act on our decisions regarding problems," each rated on a 4-point scale (1 = Strongly Disagree to $4=$ Strongly Agree). The items have demonstrated adequate concurrent and discriminant validity from previous research (Miller, Epstein, Bishop, \& Keitner, 1985). Cronbach's alpha for youth report in this sample was .87. Cronbach's alpha for parent report was .83. Because the participants being studied were members of the same family, the observations were not independent. In order to account for this, youth and parent reports were averaged to create a composite score of family problem-solving for our analyses.

\section{Risk-Taking Behavior}

\section{Youth}

Youth-reported risk-taking behavior was measured using the 10-item delinquent behavior scale (Elliott, Huizinga, \& Ageton, 1985). Youth indicated how many days in the last month they had engaged in a number of delinquent activities. Respondents answered each item on a slider scale ranging from 0 to 30 . The scale was found to be reliable $(\alpha=.85)$. Because little is known about the relationships between family problem-solving, attachment, and adolescent risk-taking behavior, we chose to examine the breadth of engagement in risk-taking behavior, rather than parse out specific risk-taking behaviors that may be mediated by family problem-solving. Following previous research (Garrido et al., 2017), three dichotomous risk-taking categories (substance use, violence, and general delinquency) were constructed and summed. Four items were used to assess substance use: "drank alcohol," "got drunk," "used marijuana," and "smoked cigarettes"; one item measured violence: "hit someone or got into a physical fight"; and, five items assessed general delinquency: "spray paint on place you're not supposed to," "damaged property," "snuck into someplace without paying," "took something from a store without paying," "stole something (other than from a store)." The sum of the three categorical variables represents total engagement in risk-taking behavior, $(0=$ no risk-taking behaviors, 3 $=$ engagement in risk-taking behaviors across all three categories). 


\section{Parents}

Parent-report of risk-taking behavior was assessed via the 5-item conduct problems subscale of the Strengths and Difficulties Questionnaire (SDQ; Goodman, 1997). Parents were asked to rate the extent to which they believed each item was true of their child's behavior over the last six months on a 3-point scale from not true to certainly true. Items included behaviors such as "steals from home, school or elsewhere." Cronbach's alpha was .76.

\section{Data Analysis}

Before testing study hypotheses, preliminary data analyses were conducted, examining the relationships among study variables (see Tables 1 and 2), checking for missing data, and checking the normality of study variables. Due to the high percentage of missing data on parent report of family problem-solving (12.2\%), full information maximum likelihood, a preferred missing data technique which estimates parameters based on existing data, was used (McKnight, McKnight, Sidani, \& Figueredo, 2007). All of the study variables were normally distributed.

Table 1. Descriptive Statistics of Family Problem-Solving, Attachment Quality, and Risk-Taking Measures

\begin{tabular}{|l|c|c|c|c|c|c|c|}
\hline Variable & Min & Max & M & Mdn & SD & Skewness & Kurtosis \\
\hline $\begin{array}{l}\text { Family problem-solving } \\
\text { (composite of youth and parent) }\end{array}$ & 1.2 & 4.0 & 2.93 & 2.9 & .43 & -.305 & .778 \\
\hline Attachment quality & 1.2 & 3.0 & 2.37 & 2.43 & .41 & -.64 & -.136 \\
\hline Risk-taking (Youth) & 0.0 & 3.0 & .650 & 0.0 & .92 & 1.23 & .384 \\
\hline Risk-taking (Parent) & 1.0 & 3.0 & 1.63 & 1.6 & .49 & .519 & -.564 \\
\hline
\end{tabular}

Research suggests age and gender differences exist on risk-taking (Chassin, 2008; Institute of Medicine \& National Research Council (IOM \& NRC), 2011). Rates of substance use tend to be higher for males than for females (Barnes, Welte, Hoffman, \& Tidwell, 2009; Cotto et al., 2010), and for most adolescents, substance use is reduced or stopped in early young adulthood (IOM 
\& NRC, 2011). Furthermore, males are more likely to engage in aggressive behaviors (Chun \& Mobley, 2010; Nichols, Graber, Brooks-Gunn, \& Botvin, 2006), therefore, age and gender were entered as control variables. Race/ethnicity was also entered as a control variable, as research has shown that racial/ethnic differences in risk-taking exist (Barnes et al., 2009). For instance, African Americans youth tend to have lower rates of alcohol and cigarette use than White youth (Johnston, O’Malley, Miech, Bachman, \& Schulenberg, 2016).

To test the hypotheses, two path analyses were conducted to assess if (a) attachment was associated with parent-report (path analysis 1 ) and youth-report (path analysis 2) of adolescent risk-taking behavior, (b) attachment was associated with family problem-solving ability, (c) family problem-solving ability was associated with parent and youth report of adolescent risktaking behavior, and (d) family problem-solving ability mediated the relationship between attachment and risk-taking behavior (i.e., parent report and youth report). Traditionally, mediation analysis has been guided by the Baron and Kenny (1986) causal steps approach. While a majority of previously published mediation analyses follow the causal steps approach, it has become less popular due to criticism from a number of quantitative methodologists (Hayes, 2009, 2012; MacKinnon, Fairchild, \& Fritz, 2007), who argue that the causal steps approach fails to formally quantify the indirect effect, nor does it require any inferential test (Hayes, 2012). Furthermore, a true mediational relationship may exist even if some of the relationships are not found (MacKinnon et al., 2007). For these reasons, two path models testing mediation were used in this study. For both models, path analysis testing mediation was run using MPlus 8 (Muthén \& Muthén, 1998-2017). Rather than following the causal steps approach to mediation, MPlus generates the simple mediation model simultaneously. A number of goodness-of-fit measures were used to assess model fit including root mean square error of approximation (RMSEA), and the comparative fit index (CFI). In general, the cutoff for acceptable model fit is .08 or lower for RMSEA and 0.90 or higher for CFI (Hu \& Bentler, 1999).

In the first model, parent-report of risk-taking behavior was the outcome variable, attachment was the independent variable, and family problem-solving was the mediator variable. Age, gender, and race were covariates. The second model was the same, except youth-report of risk-taking behavior was the outcome variable. Control variables, attachment, and family problem-solving were simultaneously entered and regressed on the dependent variable (i.e., parent-reported conduct problems, youth-reported delinquent behavior). 


\section{Results}

\section{Correlations}

Table 2 shows the correlations among family problem-solving, attachment, parent and youth report of risk-taking, and youth age. Results indicated a positive correlation between family problem-solving and attachment and a negative correlation between family problem-solving and parent and youth report of risk-taking behavior. Attachment was negatively correlated with parent and youth report of risk-taking.

Table 2. Correlations Between Key Study Variables

\begin{tabular}{|l|c|c|c|c|c|}
\hline Variables & $\mathbf{1}$ & $\mathbf{2}$ & $\mathbf{3}$ & $\mathbf{4}$ & $\mathbf{5}$ \\
\hline 1. Family problem-solving & & $.547 * *$ & $-.203^{* *}$ & $-.163 * *$ & -.077 \\
\hline 2. Attachment quality & & & $-.298^{* *}$ & $-.144 *$ & $-.174 * *$ \\
\hline 3. Risk-taking (Youth) & & & & $.301 * *$ & .095 \\
\hline 4. Risk-taking (Parent) & & & & & -.103 \\
\hline 5. Youth age & & & & & \\
\hline
\end{tabular}

Note. $* p \leq .05, * * p \leq .01$

Two independent-sample $t$-tests were conducted to compare family problem-solving, attachment, parent and youth report of risk-taking, and youth age scores for male and female youth and for white and minority youth. There was a significant difference in the family problem-solving scores for males $(M=2.99, S D=.411)$ and females $(M=2.83, S D=.452)$; $t(268)=-3.13, p<.01)$, and in attachment scores for males $(M=2.46, S D=.370)$ and females $(M=2.24, S D=.45) ; t(199.4)=-4.20, p<.01)$. Results indicated that males $(M=$ $1.68, S D=.522)$ scored higher on parent report of risk-taking than females $(M=1.56, S D=$ $.427 ; t(253.11)=-2.08, p<.05)$. No significant differences in family problem-solving, attachment, risk-taking, or youth age scores between white and minority youth were found.

\section{Path Analysis 1: Parent-Reported Risk-Taking}

Simple mediation analysis using ordinary least squares regression was conducted to investigate the direct and indirect effects of attachment and family problem-solving ability on parent-report of adolescent risk-taking, controlling for age, gender, and race/ethnicity. Control variables, 
attachment, family problem-solving ability, and parent-reported risk-taking behavior were simultaneously entered for the path model. The model had adequate fit (CFI $=0.93$, RMSEA $=$ 0.079). Results indicated that the direct paths ( $a$ and $c^{\prime}$ ) were statistically significant (see Figure 1 and Table 3). Attachment quality was a significant predictor of parent-reported risk-taking behavior, $b=-.168, S E=.060, p<.01$, providing evidence to support hypothesis 1 . Attachment quality was also a significant predictor of family problem-solving ability, $b=.611$, $S E=.040, p<.001$, providing support for hypothesis 2 . Family problem-solving ability, however, was not a significant predictor of parent-reported risk-taking, $b=-.083, S E=.055, p$ $=.13$, controlling for age, gender, and race/ethnicity, offering no support for hypothesis 3 . The indirect effect of parent-reported risk-taking modeled on attachment quality was not significant; we did not find evidence to support hypothesis 4 that the relationship between attachment quality and parent-report of risk-taking behavior was mediated by family problem-solving ability.

Figure 1. Mediation Model for the Effects of Attachment Quality and Family ProblemSolving Ability on Adolescent Risk-Taking Behavior.

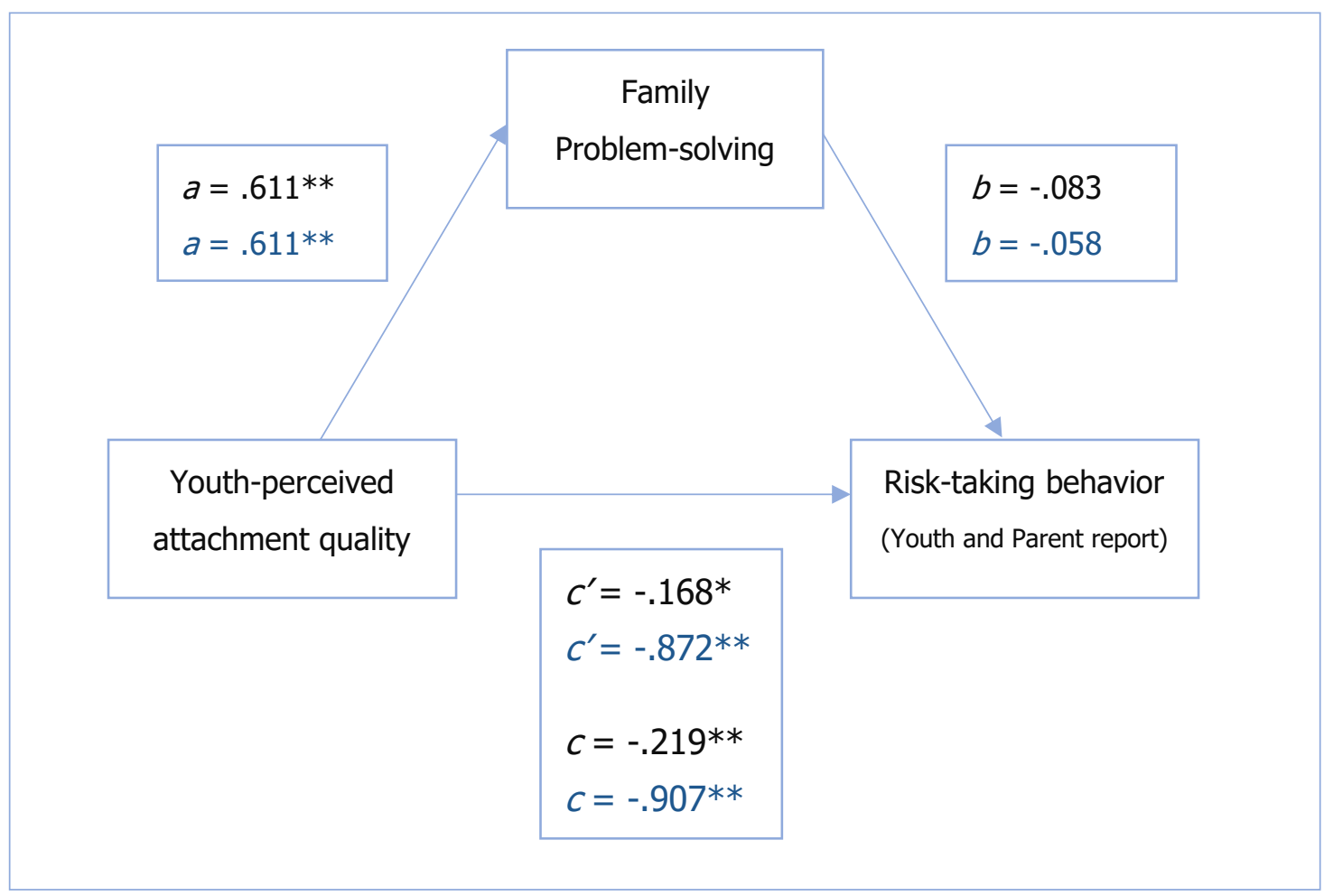

Note: Coefficients for parent model in black; coefficients for youth model in blue.

${ }^{*} p<.05, * * p<.001$ 
Table 3. Path Model Summary for Family Problem-Solving and Attachment Quality Predicting Parent-Reported Risk-Taking $(N=520)$

\begin{tabular}{|l|c|c|c|c|}
\hline Variable & $\boldsymbol{B}$ & $\boldsymbol{S E} \boldsymbol{B}$ & $\boldsymbol{p}$ & $\boldsymbol{R}^{\mathbf{2}}$ \\
\hline & & & & .043 \\
\hline Family problem-solving & -.083 & .055 & .13 & \\
\hline Attachment quality & -.168 & .060 & $<.01$ & \\
\hline
\end{tabular}

\section{Path Analysis 2: Youth Reported Risk-Taking}

In the second model, ordinary least squares regression was conducted to investigate the mediating effect of family problem-solving ability on the relationship between attachment quality and youth report of adolescent risk-taking behavior, after controlling for age, gender, and race/ethnicity. Control variables, attachment quality, family problem-solving ability, and youth-reported risk-taking behavior, were simultaneously entered for the ordinary least squares regression model. The model had good fit (CFI $=.994$, RMSEA $=0.024$ ). Results suggested that two of the three direct paths ( $a$ and $c^{\prime}$ ) were statistically significant (see Figure 1 and Table 4). Attachment quality was a significant predictor of youth-reported risk-taking behavior, $b=-$ .872 , SE $=.151, p<.001$, (Figure 1) providing support for hypothesis 1 . Attachment quality was a significant predictor of family problem-solving ability, $\mathrm{b}=.611$, $\mathrm{SE}=.039, p<.001$, providing evidence to support hypothesis 2 , however, family problem-solving ability was not a significant predictor of youth-reported risk-taking behavior $\mathrm{b}=-.058, \mathrm{SE}=.169, p=.73$, controlling for age, gender, and race/ethnicity. The indirect effect of youth-reported risk-taking modeled on attachment quality was not significant, thus, the results do not support the hypothesis that the relationship between attachment and youth-reported risk-taking behavior was mediated by family problem-solving ability. 
Table 4. Path Model Summary for Family Problem-Solving and Attachment Quality Predicting Youth-Reported Risk-Taking $(N=520)$

\begin{tabular}{|l|c|c|c|c|}
\hline Variable & $\boldsymbol{B}$ & SE B & $\boldsymbol{P}$ & $\boldsymbol{R}^{2}$ \\
\hline & & & & .086 \\
\hline Family problem-solving & -.096 & .154 & .535 & \\
\hline Attachment quality & -.690 & .171 & $<.001$ & \\
\hline
\end{tabular}

\section{Discussion}

This study sought to examine the associations between attachment quality, family problemsolving, and adolescent risk-taking behavior, and to examine the mediating effect of family problem-solving ability on the relationship between attachment quality and adolescent risktaking behavior. Results demonstrate that parental bonds continue to play a protective role in the lives of adolescents. Consistent with the proposed theoretical assumptions, adolescents with greater attachment to their caregivers reported higher levels of family problem-solving abilities and lower levels of reported risk-taking by both parents and youth. These findings align with previous empirical studies regarding risk-taking (e.g., Barfield-Cottledge, 2015; HammePeterson, Buser, \& Westburg, 2010), and provide evidence of the association between parentchild attachment quality and family problem-solving ability. Consistent with attachment and family systems theories, having a secure bond with a caregiver appears to promote a context for family problem-solving, in which families are able to manage problems effectively while promoting healthy family functioning.

While research has shown that securely attached teens tend to handle conflicts with parents by engaging in productive problem-solving discussions (Allen, 2008; Allen et al., 2003), to our knowledge this is the first study to test the association between parent-child attachment quality and family-level problem-solving ability outside of the context of parent-child conflict. Our hypothesis that family problem-solving ability would be negatively associated with adolescent risk-taking behavior, however, was not supported. Similarly, our hypothesis that family problem-solving ability would mediate the effect of attachment quality on adolescent risk-taking behavior was not supported. First and foremost, it appears that family problem-solving ability is not the mechanism by which parent-child relationships quality affects risk-taking during 
adolescents. Even though attachment quality and family problem-solving were associated, the link to risk-taking was not found in our analyses. Because family problem-solving has been associated with the development of mastery (i.e., the sense of having control over the forces that affects one's life) during adolescence (Conger, Williams, Little, Masyn, \& Shebloski, 2009), future research should consider whether, and how, family problem-solving affects other developmental outcomes.

One possible explanation for the lack of association between family problem-solving and adolescent risk-taking is that family problem-solving ability may look different for single-parent families compared to two-parent families. FST would support the potential differences between the composition and influence of different types of systems. Results of an independent samples $t$ test, comparing caregivers who were married or living with a partner $(58.9 \%)$ and caregivers who were single $(41.1 \%)$, revealed higher composite family problem-solving scores for families with married caregivers $(M=2.95)$ than for families with single caregivers $(M=2.86)$. Research suggests that difficulties related to family functioning exist for single-parent families (Moore \& Vandivere, 2000). Many single-parent families have been found to have difficulties related to their family structure, such as less time to carry out parenting tasks (Cooney \& Mortimer, 1999). In general, single-parent families have lower socioeconomic status (SES) than two-parent families (Amato, 2000). Single parents have additional obligations such as spending more time away from the home working to support their family thus, spending less time together (Kendig \& Bianchi, 2008). Tentatively, it may be that when parents can share the responsibility of parenting, there is more time and attention available to cultivate family problem-solving abilities. Further examination of the family structure differences in the relationships between attachment quality, family problem-solving, and adolescent risk-taking should be conducted.

\section{Limitations}

Several limitations of the study deserve note. First, because data were gathered from one public, Western university, the findings have limited generalizability beyond the present sample. While the sample represented a somewhat diverse population (i.e., $42.9 \%$ identified with ethnic groups other than Caucasian) it is unclear the degree to which these findings are generalizable beyond the present sample. By examining the relationships between attachment, family problem-solving, and risk-taking behavior using larger, more diverse samples, differences in the function of family problem-solving among different cultures may be identifiable. Second, including both parent and youth reports of adolescent risk-taking behavior provides a more 
complete picture, but the reliance on self-report of parents and adolescents subjects our results to recall bias. It may also be that youth were reluctant to reveal the actual extent of their risktaking behavior for fear that their parents would find out or that they would get into trouble, and that caregivers underreported reported their child's risk-taking involvement due to inaccuracy of memory, or general lack of knowledge. Third, limitations surrounding the use of secondary data were present. For instance, the concept of risk-taking varied by reporter, such that youth report of risk-taking included a wider range of risk-taking behaviors (i.e., substance use, general delinquency, violence) than the parent-report measure. Lastly, because attachment quality was based on the youth report only, results may not reflect a complete representation of the attachment relationship.

\section{Implications and Future Directions}

Significant relationships were found between parent-child attachment quality and adolescent risk-taking behavior, and between parent-child attachment quality and family problem-solving. These relationships provide empirical support for the recommendation that intervention efforts should include family-level approaches. In risk-taking preventive interventions, parents should be trained on establishing and maintaining secure, close relationships with their child especially during adolescent development. This recommendation is consistent with prior research on mitigating risk-taking behavior (Mogro-Wilson, 2008; Yun, et al., 2016). Programs that target the quality of the attachment as assessed through the IPPA in the current study between parent and child may be particularly effective. Promoting acceptance and supportive bonds between parents and youth may aid families in preventing youth engagement in a wide range of risktaking behavior by contributing to adolescents' development of perceived confidence in their ability to resist social pressures to engage in risk-taking behavior. The 15-item short form IPPA scale used in this study may also be a useful screening tool for identifying families whose children are at risk for engagement in health-risk behaviors, or as an assessment tool for gauging response to services.

Because attachment quality was associated with family problem-solving, it is also useful to consider implications for improving family problem-solving. Family problem-solving may be related to other constructs such as conflict and conflict resolution, which have been identified as an important factor in the development of antisocial behavior (Dishion, Forgatch, Van Ryzin, \& Winter, 2012). In families with high quality parent-child relationships, family problem-solving may be more readily apparent and useful, which may facilitate other positive processes, such as conflict management within interpersonal relationships. More research is needed to tease out 
the relationships among these related constructs, but practically, an effort to improve the parent-child bond is warranted and may decrease vulnerability for risk-taking while also increasing family problem-solving.

Although family problem-solving was not a significant predictor of adolescent risk-taking in the current study, it may be that another family-level behavior such as parent-child communication is the mechanism by which attachment quality relates to adolescent risk-taking. Prior research suggests inverse relationships between parent-child communication, substance use, and other deviant behaviors (Barnes, Farrell, \& Banerjee, 1994; Johnson, Su, Gerstein, Shin, \& Hoffman, 1995; Kafka \& London, 1991; Moitra \& Mukherjee, 2012). It may be that adolescents with greater attachment quality to a caregiver will have higher levels of satisfaction of parent-child communication, which could in turn be associated with less engagement in risk-taking behavior. It could also be that having greater attachment quality to a caregiver is associated with having more open communication between parents and adolescents, which in turn is negatively associated with adolescent risk-taking. Another mechanism could be parental monitoring, as research has shown that adolescents who are well-monitored are less likely to engage in risktaking behaviors including substance use (Dever et al. 2012; Dishion \& McMahon, 1998). It could be that having greater attachment quality to a caregiver is associated with more appropriate parental monitoring which in turn leads to decreased risk-taking. Further research should consider these alternative mechanisms when examining the relationship between attachment quality and adolescent risk-taking behavior in order to develop successful prevention and intervention approaches.

\section{References}

Ahmadi, K. M., Azad-Marzabadi, E., Ashrafi, S., \& Raiisi, F. (2007). Construction and validation of family problem solving scale. Journal of Applied Sciences, 724$)$, 3958-3964. doi:10.3923/jas.2007.3958.3964

Allen, J. P. (2008). The attachment system in adolescence. In J. Cassidy \& P.R. Shaver (Eds.), Handbook of attachment: Theory, research, and clinical applications ( $2^{\text {nd }}$ ed., pp.857-879). New York, NY: Guilford Press.

Allen, J. P., McElhaney, K. B., Land, D. J., Kuperminc, G. P., Moore, C. W., O'Beirne-Kelly, H., \& Kilmer, S. L. (2003). A secure base in adolescence: Markers of attachment security in the motheradolescent relationship. Child Development, 74(1), 292-307. 
Family Problem Solving, Attachment, Risk-Taking

Amato, P. R. (2000). The consequences of divorce for adults and children. Journal of Marriage and the Family, 62(4), 1269-1287.

Barfield-Cottledge, T. (2015). The triangulation effects of family structure and attachment on adolescent substance use. Crime \& Delinquency, 61(2), 297-320.

Barnes, G. M., Farrell, M. P., \& Banerjee, S. (1994). Family influences on alcohol abuse and other problem behavior among black and white adolescents in a general population sample. Journal of Research on Adolescence, 4, 183-201. doi:10.1207/s15327795jra0402_2

Barnes, G., Welte, J., Hoffman, J., \& Tidwell, M. (2009). Gambling, alcohol, and other substance use among youth in the United States. Journal of Studies on Alcohol and Drugs, 70(1), 134-42.

Baron, R. M., \& Kenny, D. A. (1986). The moderator-mediator variable distinction in social psychological research: Conceptual, strategic, and statistical considerations. Journal of Personality and Social Psychology, 51, 1173-1182.

Borduin, C., Henggeler, S., Hanson, C., \& Pruitt, J. (1985). Verbal problem solving in families of fatherabsent and father-present delinquent boys. Child \& Family Behavior Therapy, 72), 51-64. doi:10.1300/J019v07n02_04

Boss, P. G., Doherty, W. J., LaRossa, R., Schumm, W. R., \& Steinmetz, S. K. (1993). Sourcebook of Family Theories and Methods: A contextual Approach. New York: Plenum Press.

Botvin, G. J., Malgady, R. G., Griffin, K. W., Scheier, L. M., \& Epstein, J. A. (1998). Alcohol and marijuana use among rural youth: Interaction of social and intrapersonal influences. Addictive Behaviors, 23(3), 379-387. doi:10.1016/S0306-4603(98)00006-9

Bowlby, J. (1982). Attachment and loss: Vol. 1. Attachment ( $2^{\text {nd }}$ ed. $)$. New York, NY: Basic Books. (Original work published 1969)

Cassidy, J. (2001). Truth, lies, and intimacy: An attachment perspective. Attachment \& Human Development, 3(2), 121-155. doi:10.1080/14616730110058999

Cassidy, J., \& Shaver, P. (2008). Handbook of attachment: Theory, research, and clinical applications (2 ${ }^{\text {nd }}$ ed.). New York: Guilford Press.

Chassin, L. (2008). Adolescent substance use: Patterns and trends. Presentation at the Workshop on Individual Processes and Adolescent Risk Behavior, National Academies, Washington, DC.

Chassin, L., Curran, P. J., Hussong, A. M., \& Colder, C. R. (1996). The relation of parent alcoholism to adolescent substance use: A longitudinal follow-up study. Journal of Abnormal Psychology, 105(1), 70-80. doi:10.1037/10248-020

Chun, H., \& Mobley, M. (2010). Gender and grade-level comparisons in the structure of problem behaviors among adolescents. Journal of Adolescence, 33, 197-207. doi:10.1016/j.adolescence.2009.03.010 
Conger, K. J., Williams, S. T., Little, W. M., Masyn, K. E., \& Shebloski, B. (2009). Development of mastery during adolescence: The role of family problem-solving. Journal of Health and Social Behavior, 50(1), 99-114. doi:10.1177/002214650905000107

Cooney, T., \& Mortimer, J. (1999). Family structure differences in the timing of leaving home: Exploring mediating factors. Journal of Research on Adolescence, 9(4), 367-394. doi:10.1207/s15327795jra0904_1

Cooper, M. L., Shaver, P. R., \& Collins, N. L. (1998). Attachment styles, emotion regulation, and adjustment in adolescence. Journal of Personality and Social Psychology, 74(5), 1380-1397.

Cotto, J. H., Davis, E., Dowling, G. J., Elcano, J. C., Staton, A. B., \& Weiss, S. R. (2010). Gender effects on drug use, abuse, and dependence: A special analysis of results from the national survey on drug use and health. Gender Medicine, 75), 402-413. doi:10.1016/j.genm.2010.09.004

Dever, B., Schulenberg, V., Dworkin, J., O'Malley, E., Kloska, J., \& Bachman, B. (2012). Predicting riskraking with and without substance use: The effects of parental monitoring, school bonding, and sports participation. Prevention Science, 13(6), 605-615. doi:10.1007/s11121-012-0288-z

DiClemente, R. J., Santelli, J. S., \& Crosby, R. A. (2009). Adolescent Health: Understanding and Preventing Risk Behaviors. (1 ${ }^{\text {st }}$ ed.). Hoboken, NJ: Jossey-Bass.

Dishion, T. J., Forgatch, M., Van Ryzin, M., \& Winter, C. (2012). The nonlinear dynamics of family problem solving in adolescence: The predictive validity of a peaceful resolution attractor. Nonlinear Dynamics, Psychology, and Life Sciences, 16(3), 331-352.

Dishion, T., \& McMahon, J. (1998). Parental monitoring and the prevention of child and adolescent problem behavior: A conceptual and empirical formulation. Clinical Child and Family Psychology Review, 1(1), 61-75. doi:10.1023/A:1021800432380

D'Zurilla, T. J., \& Nezu, A. M. (1999). Problem-solving therapy: A social competence approach to clinical intervention ( $2^{\text {nd }}$ ed.). New York: Springer.

D'Zurilla, T. J., Nezu, A. M., \& Maydeu-Olivares, A. (2007). Social problem solving: Theory and assessment. In E. C. Chang, T. J. D'Zurilla, \& L. J. Sanna (Eds.), Social problem solving: Theory, research, and training (pp. 11-27). Washington, DC: American Psychological Association.

Elliott, D. S., Huizinga, D., \& Ageton, S. S. (1985). Explaining Delinquency and Drug Use. (1 ${ }^{\text {st }}$ ed.). Beverly Hills, CA: Sage.

Epstein, N. B., Baldwin, L. M., \& Bishop, D. S. (1983). The McMaster family assessment device. Journal of Marital and Family Therapy, 9(2), 171-180. doi:10.1111/j.1752-0606.1983.tb01497.x

Garrido, E. F., Weiler, L. M., \& Taussig, H. N. (2017). Adverse childhood experiences and health-risk behaviors in vulnerable early adolescents. Journal of Early Adolescence, 027243161668767. doi: $10.1177 / 0272431616687671$

Gifford-Smith, M. (2000). People in my life [online]. Retrieved from http://www.fasttrackproject.org/techrept/p/pml/pml5tech.pdf. 
Goodman, R. (1997). The Strengths and Difficulties Questionnaire: A Research Note. Journal of Child Psychology and Psychiatry, 38, 581-586.

Grossmann, K., Grossmann, K. E., Kindler, H., \& Zimmermann, P. (2008). A wider view of attachment and exploration: The influence of mothers and fathers on the development and psychological security from infancy to young adulthood. In J. Cassidy \& P. R. Shaver (Eds.), Handbook of attachment: Theory, research, and clinical applications (2 ${ }^{\text {nd }}$ ed., pp.857-879). New York, NY: Guilford Press.

Haggerty, K. P., Skinner, M. L., Catalano, R. F., Abbott, R. D., \& Crutchfield, R. D. (2015). Long-term effects of staying connected with your teen $\circledast$ on drug use frequency at age 20 . Prevention Science, 16(4), 538-549. doi:10.1007/s11121-014-0525-8

Hamme-Peterson, C., Buser, T. J., \& Westburg, N. G. (2010). Effects of familial attachment, social support, involvement, and self-esteem on youth substance use and sexual risk taking. The Family Journal, 18(4), 369-376.

Hawkins, J. D., Catalano R. F., \& Miller J. Y. (1992). Risk and protective factors for alcohol and other drug problems in adolescence and early adulthood: Implications for substance abuse prevention. Psychological Bulletin, 112(1), 64-105. doi:10.1037/0033-2909.112.1.64

Hayes, A. F. (2009). Beyond Baron and Kenny: Statistical mediation analysis in the new millennium. Communication Monographs, 76(4), 408-420. doi:10.1080/03637750903310360

Hayes, A. F. (2012). PROCESS: A versatile computational tool for observed variable mediation, moderation, and conditional process modeling. Retrieved from http://www.afhayes.com/public/process2012.pdf

Herrera, C., DuBois, D. L., \& Grossman, J. B. (2013). The role of risk: Mentoring experiences and outcomes for youth with varying risk profiles. New York, NY: A Public project distributed by MDRC.

Hops, H., Tildesley, E., Lichtenstein, E., Ary, D., \& Sherman, L. (1991). Parent-adolescent problemsolving interactions and drug use. American Journal of Drug and Alcohol Abuse, 16, 239-258. doi:10.3109/00952999009001586

Hu, L. T., \& Bentler, P. M. (1999). Cutoff criteria for fit indexes in covariance structure analysis: Conventional criteria versus new alternatives. Structural Equation Modeling: A Multidisciplinary Journal, 6(1), 1-55. doi:10.1080/10705519909540118

Institute of Medicine \& National Research Council. (2011). The science of adolescent risk-taking: Workshop report. Committee on the Science of Adolescence. Washington, DC: The National Academies Press.

Irwin, C. E. (1993). Adolescence and risk taking: How are they related? In N.J. Bell \& R.W. Bell (Eds.), Adolescent risk taking (pp.7-28). Thousand Oaks, CA: Sage Publications. 
Family Problem Solving, Attachment, Risk-Taking

Jaffee, W. B., \& D'Zurilla, T. J. (2003). Adolescent problem solving, parent problem solving, and externalizing behavior in adolescents. Behavior Therapy, 34(3) 295-311. doi:10.1016/S00057894(03)80002-3

Johnson, R. A., Su, S. S., Gerstein, D. R., Shin, H. C., \& Hoffman, J. P. (1995). Parental influences on deviant behavior in early adolescence: $\mathrm{A}$ logistic response analysis of age and gender-differential effects. Journal of Quantitative Criminology, 11(2), 167-193. doi:10.1007/BF02221122

Johnston, L. D., O'Malley, P. M., Miech, R. A., Bachman, J. G., \& Schulenberg, J. E. (2016). Monitoring the Future national survey results on drug use, 1975-2015: Overview, key findings on adolescent drug use. Ann Arbor: Institute for Social Research, The University of Michigan.

Kafka, R. R., \& London, P. (1991). Communication in relationships and adolescent substance use: The influence of parents and friends. Adolescence, 26, 587-598.

Kendig, S. M., Bianchi, S. M. (2008). Single, cohabitating, and married mothers' time with children. Journal of Marriage and Family, 70(5), 1228-1240. doi:10.1111/j.1741-3737.2008.00562.x

Kobak, R. R., Cole, H. E., Ferenz-Gillies, R., Fleming, W. S., \& Gamble, W. (1993). Attachment and emotion regulation during mother-teen problem solving: A control theory analysis. Child Development, 64(1), 231-245.

Li, J., Delvecchio, E., Lis, A., Nie, Y., \& Di Riso, D. (2015). Parental attachment, self-control, and depressive symptoms in Chinese and Italian adolescents: Test of a mediation model. Journal of Adolescence, 43, 159-170. doi:10.1016/j.adolescence.2015.06.006

Mackinnon, D. P., Fairchild, A. J., \& Fritz, M. S. (2007). Mediation Analysis. Annual review of psychology, 58, 593-614. doi:10.1146/annurev.psych.58.110405.085542

McKnight, P. E., McKnight, K. M., Sidani, S., \& Figueredo, A. J. (2007). Missing data: A gentle introduction. New York, NY: Guilford Press.

Miller, I. W., Epstein, N. B., Bishop, D. S., \& Keitner, G. I (1985). The McMaster Family Assessment Device: Reliability and validity*. Journal of Marital and Family Therapy, 11(4), 345-356. doi:10.1111/j.1752-0606.1985.tb00028.x

Miller, I. W., Ryan, C. E., Keitner, G. I., Bishop, D. S., \& Epstein, N. B. (2000). The McMaster approach to families: Theory, assessment, treatment and research. Journal of Family Therapy, 22(2), 168189. doi:10.1111/1467-6427.00145

Mogro-Wilson, C. (2008). The influence of parental warmth and control on Latino adolescent alcohol use. Hispanic Journal of Behavioral Sciences, 30(1), 89-105. doi:10.1177/0739986307310881

Moitra, T., \& Mukherjee, I. (2012). Parent-adolescent communication and delinquency: A comparative study on Kolkata, India. Europe's Journal of Psychology, 8(1), 74-95. doi:10.5964/ejop.v8i1.299

Montemayor, R. (1986). Family variation in parent-adolescent storm and stress. Journal of Adolescent Research, 1(1), 15-31. doi:10.1177/074355488611003 
Family Problem Solving, Attachment, Risk-Taking

Moore, K., \& Vandivere, S. (2000). Stressful family lives: Child and parent well-being. Retrieved May 5, 2017 from http://www.urban.org/url.cfm?id=309565

Mushtaq, A. (2007). Aggressive children's status among peers and their social information processing styles (Unpublished M. Phil. dissertation). National Institute of Psychology, QuaidAzam University, Islamabad, Pakistan.

Muthén, L. K., \& Muthén, B. O. (1998-2017). Mplus User's Guide. ( $8^{\text {th }}$ ed.). Los Angeles, CA: Muthén \& Muthén.

Nichols, T. R., Graber, J. A., Brooks-Gunn, J., \& Botvin, G. J. (2006). Sex differences in overt aggression and delinquency among urban minority middle school students. Journal of Applied Developmental Psychology, 271), 78-91. doi:10.1016/j.appdev.2005.12.006

Pequegnat, W. \& Szapocznik, J. (2000). The role of families in preventing and adapting to HIV/AIDS: Issues and answers. In W. Pequegnat \& J. Szapocznik (Eds.), Working with families in the era of HIV/AIDS (pp. 3-26). Thousand Oaks, CA: Sage.

Pilgrim, C. C., Schulenberg, J. E., O'Malley, P. M., Bachman, J. G., \& Johnston, L. D. (2006). Mediators and moderators of parental involvement on substance use: A national study of adolescents. Prevention Science, 71 ), 75-89. doi:10.1007/s11121-005-0019-9

Robin, A. L., \& Foster, S. (1989). Negotiating parent-adolescent conflict: A behavioral-family systems approach. New York, NY: Guilford Press.

Sarracino, D. \& Innamorati, M. (2012). Attachment, social value orientation and at-risk behavior in early adolescence. In C. Bassani (Ed.), Adolescent behavior (pp.97-116). New York: Nova Publishers.

Vuchinich, S. (2004). Problem-solving training for families. In E.C., Chang, T. J., D'Zurilla, \& L. J., Sanna (Eds.), Social problem solving: Theory, research, and training (pp. 209-222). Washington, DC: American Psychological Association.

Vuchinich, S., Wood, B., \& Vuchinich, R. (1994). Coalitions and family problem solving with preadolescents in referred, at-risk, and comparison families. Family Process, 33(4), 409-424. doi:10.1111/j.1545-5300.1994.00409.x

Weiler, L. M., Haddock, S., Henry, K. L., Zimmerman, T. S., Krafchick, J., \& Youngblade, L. (2015). Timelimited, structured youth mentoring and adolescent problem behaviors. Applied Developmental Science, 9(4), 196-205. doi:10.1080/10888691.2015.1014484

Yun, H.-J., Cui, M., \& Blair, B. L. (2016). The mediating roles of adolescent disclosure and parental knowledge in the association between parental warmth and delinquency among Korean adolescents. Journal of Child and Family Studies, 25(8), 2395-2404. doi:10.1007/s10826-0160425-6 